\title{
Definition of the lower extremity overuse: A review
}

\author{
Darja Nesterovica
}

Military Medicine Research and study centre, Rīga Stradinš̌ University, Riga, Latvia

\begin{abstract}
Injuries of the lower extremity overuse are common among different adult populations with high physical demands such as athletes and soldiers. Contradiction exists among used different definitions of overuse injury. Objective: to identify most common overuse injury definition and propose overuse injury criteria based on recent literature review. Methods: literature review of the most recent literature about lower extremity overuse injuries published between 2013 and June 2018. Studies retrieved through MEDLINE, PubMEd and ScienceDirect, applying inclusion and exclusion criteria and language restrictions. Results: 18 articles met all inclusion criteria out of 2995 articles screened. Included research populations are different sport athletes $(n=11)$ and soldiers $(n=5)$. Most studies described such overuse injuries as lower extremity stress fractures $(n=10)$ and Achilles tendinopathy $(n=7)$. Most reported overuse injury definition injury due to large amount of physical activity training $(n=8)$ or repetitive micro-trauma $(n=4)$, Conclusions: lower extremity overuse injury is an injury due to high physical load because of incomplete repair process and with gradual onset. Important criteria for defining overuse injury include absence of known single traumatic event, progressive symptoms and lack of recovery period.
\end{abstract}

Key words: overuse injury, lower extremity, review.

\section{Background}

Lower extremity musculoskeletal overuse injuries are common among different adult population with high physical demands, such as different sports athletes and military population. Overuse injuries may cause significant pain and, as a consequence, reduced function and psychological exhaustion $[1,2]$. Overuse injury is the result of repeated microtrauma due to high physical load with no single, identifiable event, but acute injuries are typically caused by a single traumatic event, e.g. fall [3, 4]. Synonyms for overuse injury include cumulative micro-trauma or repetitive strain injury $[5,6]$. Diagnoses of the lower extremity overuse injury are different musculoskeletal injuries with " $M$ " and few "S" codes according to $10^{\text {th }}$ Revision of International Statistical Classification of Diseases and Related Health Problems [7].

Inconsistency among "overuse" definition remain and various overuse injury definitions are used among authors [8]. Roos and Marshall in a systematic review of overuse injuries among collegiate athletes found that overuse could indicate a mechanism or a definition, and a number of studies of overuse injuries do not state the injury criteria [9]. Purpose of this study was to identify the most common overuse injury definition and propose overuse injury criteria based on recent literature review, which will help to minimise contradiction among the used definition of overuse injury. 


\section{Methods}

\subsection{Search strategy}

Most recent studies and prior reviews about lower extremity overuse injuries published between January 2013 and June 2018 retrieved through MEDLINE, PubMEd and ScienceDirect. Following search terms were used in different combinations: overuse injury OR repetitive micro-trauma OR cumulative trauma disorder AND lower extremity. The search was limited to studies among adults published in English.

\subsection{Eligibility criteria}

All identified studies were exported to the reference manager by a single investigator for abstract and full text review. Articles with lower extremity overuse definition and with overuse injury diagnoses, mentioned with available full-text, were included in this review. Studies about lower extremity overuse injuries among children or studies without mentioning precise definition or included diagnoses, as well as single case studies and book chapters were not included. From each article, all relevant information was extracted: overuse injury definition, overuse diagnoses, research design, study population type and age.

\subsection{Quality assessment}

Methodology proposed by Scottish Intercollegiate Guidelines Network (SIGN 50) was used for quality assessment. SIGN grades $1++$ (highest), 1+, 1-, 2++, 2+, 2-, 3, or 4 (lowest level of evidence) were assigned to each article [10].

\section{Results}

Out of 2995 articles screened, only 18 studies met all inclusion criteria and were included in qualitative analysis. Mainly articles were excluded because of wrong injury site (e.g. upper extremity) or missing overuse injury definition or criteria. Selection process of articles is shown in Fig. 1 (see next page).

Study populations included in analysis are different sport athletes $(n=11)$ and military personnel $(n=5)$. Lower extremity overuse injuries appear among different athletes: figure skaters, basketball and football players and military personnel (recruits and active-duty soldiers).

Most described overuse diagnoses included: M84.3 stress fractures of the lower extremity (femoral, tibial, foot; $n=10)$, M76.6 Achilles tendinopathy $(n=7)$ and S86.9 medial tibial stress syndrome $(n=7)$; M77.4 metatarsalgia $(n=2)$, S90.8 foot blisters $(n=1)$ and L84 foot skin callus $(n=1)$ also were mentioned as overuse injury.

Synonymic more and less precise overuse injury definitions were found among studies included in the analysis. Most reported overuse injury definition - injury due to large amounts of physical activity or training $(n=8)$, or repetitive micro-trauma $(n=4)$. Some authors mention overuse as the result of incomplete or maladaptive repair process $(n=2)$. Overuse injury usually is described as chronic injury with gradual onset and without a single, identifiable event responsible for the injury $(n=3)$. See Table 1 for overuse injury definitions. Studies with different research designs were observed. High quality meta-analysis as well as case series were included in this review. Results of quality assessment and study designs are shown in Table 2. 


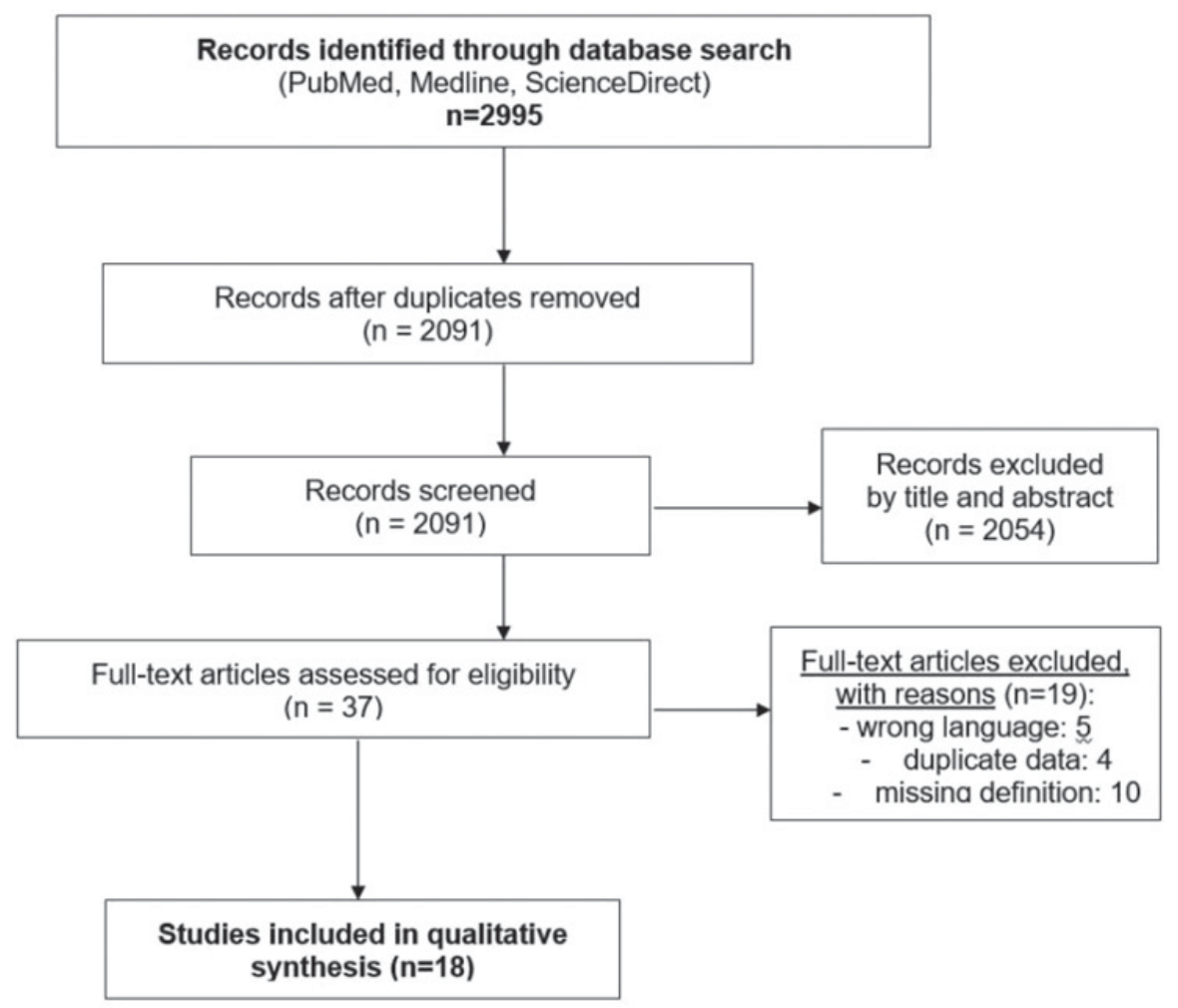

Fig. 1. Flowchart showing selection of articles.

\section{Discussion}

Purpose of this literature review was to determine the most common overuse injury definition and propose overuse injury criteria based on recent literature review. Study results showed non-compliance of overuse injury definition among researchers, despite that underlying diagnoses appear to be similar among different study populations.

Lower extremity overuse affects lower leg and foot causing different tendinopathies, stress fractures and medial tibial stress syndrome. Synonymic overuse definitions were used, but more precise overuse injury definition helps for better understanding of the nature of injury and leads to possible earlier diagnosis. Excessive load, insidious onset and lack of recovery seem to be important, but not the only components for lower extremity overuse injury. Anthropometric factors, smoking and foot posture also appear to be important factors that play role in overuse injury development $[29,30]$. Roles of other factors, such as sports shoes, stretching and biomechanics are less clear [31].

According to this literature review, the term "overuse" is appropriate when referencing chronic mechanism of injury without known traumatic event for physically active populations. This study result supports evidence from previously performed studies. As reported previously by Chéron, absence of traumatic aetiology seems automatically the result in "overuse" because the person with complaint was involved in sporting activity [32].

This review has several limitations. Firstly, only one reviewer searched and extracted the data. Secondly, publications in English with available full text were included so it is possible that some relevant articles are not included in this review. Thirdly, the quality of studies differs 
Table 1. Lower extremity overuse injury definition.

\begin{tabular}{|l|l|}
\hline First author, year of study & Overuse injury definition \\
\hline Bonanno, 2015 & $\begin{array}{l}\text { Activity-related lower limb overuse, insidious onset } \\
\text { development of overuse }\end{array}$ \\
\hline Campanelli, 2015 & $\begin{array}{l}\text { Multi-factorial injuries of the lower limb associated with } \\
\text { intensive weight bearing exercise }\end{array}$ \\
\hline Dowling, 2014 & Increased muscle strain over the period of many runs \\
\hline Foch, 2015 & Injury due to harder training \\
\hline Fullem, 2015 & $\begin{array}{l}\text { Pathologic condition that is dominated by an incomplete or } \\
\text { maladaptive repair process }\end{array}$ \\
\hline Galloway, 2013 & $\begin{array}{l}\text { Overuse injury due to required extended periods of walking } \\
\text { and marching under heavy loads. }\end{array}$ \\
\hline Goffar, 2013 & Repetitive nature of the activity - overuse \\
\hline Kerr, 2016 & Bone stress injuries \\
\hline Khan, 2018 & $\begin{array}{l}\text { Being a training or match injury when symptoms developed } \\
\text { or aggravated usually caused by repeated micro-trauma } \\
\text { without a single, identifiable event responsible for the injury }\end{array}$ \\
\hline Koch, 2016 & Overuse injuries due to large amounts of physical training \\
\hline Kollock, 2016 & $\begin{array}{l}\text { Injuries with insidious onset and no known trauma } \\
\text { mechanism }\end{array}$ \\
\hline Kristenson, 2016 & \begin{tabular}{l} 
Chronic mechanism of injury (overuse = gradually onset). \\
\hline Stress responses stemming from lack of recovery
\end{tabular} \\
\hline Malliou, 2014 & \begin{tabular}{l} 
Results of micro-trauma to bone \\
\hline Pensgaard, 2018 \\
different exercises
\end{tabular} \\
\hline Reinking, 2015 & $\begin{array}{l}\text { Deficient technical execution or frequent performance of } \\
\text { repetitive movements without sufficient recovery time. }\end{array}$ \\
\hline Sobrino, 2015 & $\begin{array}{l}\text { Overuse injuries due to large amounts of marching and } \\
\text { walking }\end{array}$ \\
\hline Sobrino, 2017 & \\
\hline Springer, 2016 & \\
\hline
\end{tabular}

Table 2. Quality assessment according to SIGN 50.

\begin{tabular}{|l|l|l|}
\hline First author, year of study & Study design & $\begin{array}{l}\text { Level of evidence, } \\
\text { SIGN 50 grades }\end{array}$ \\
\hline Bonanno, 2015 & Randomized control trial & $1(-)$ \\
\hline Campanelli, 2015 & Cross-section study & 3 \\
\hline Dowling, 2014 & Systematic review & $1(-)$ \\
\hline Foch, 2015 & Case-control study & $2(++)$ \\
\hline Fullem, 2015 & Clinical review & 4 \\
\hline Galloway, 2013 & Clinical review & 4 \\
\hline Goffar, 2013 & Cross-section study & 3 \\
\hline Kerr, 2016 & Descriptive epidemiology study & 3 \\
\hline Khan, 2018 & Case series & 3 \\
\hline Koch, 2016 & Prospective cohort & $2(++)$ \\
\hline Kollock, 2016 & Meta-analysis & $1(+)$ \\
\hline Kristenson, 2016 & Follow up-study & 3 \\
\hline Malliou, 2014 & Cross-section study & 3 \\
\hline Pensgaard, 2018 & Prospective cohort study & $2(+)$ \\
\hline Reinking, 2015 & Prospective cohort & $2(+)$ \\
\hline Sobrino, 2015 & Cross-section study & 3 \\
\hline Sobrino, 2017 & Descriptive cross-sectional study & 3 \\
\hline Springer, 2016 & Retrospective cohort & $2(-)$ \\
\hline
\end{tabular}

Note: SIGN - Scottish Intercollegiate Guidelines Network. 
significantly due to methodological distinctions and makes it difficult to provide clear lower extremity overuse definition.

\section{Conclusions}

Lower extremity overuse injury is an injury due to high physical load because of incomplete repair process and with gradual onset. Important criteria for defining overuse injury include absence of known single traumatic event, progressive symptoms and lack of recovery.

\section{References}

[1] R.P. Wilder, S. Sethi, Clin Sports Med. 23(1), 55-81 (2004)

[2] M.L. Schuer, M.S. Dietrich, West J. Med. 166(2), 104-109 (1997)

[3] C.W. Fuller, J. Ekstrand, A. Junge, Clin J. Sport Med. 16(2), 97-106 (2006)

[4] C.W. Fuller, M.G. Molloy, C. Bagate, Br. J. Sports Med. 41(5), 328-331 (2007)

[5] Z.A. Iqbal, A.H. Alghadir, J Back Musculoskelet Rehabil. 30(4), 663-666 (2017)

[6] S. Taimela, U.M. Kujala, K. Osterman, Sports Med. 9(4), 205-215 (1990)

[7] $10^{\text {th }}$ Revision of Classification of Mental and Behavioural Disorders: Clinical Descriptions and Diagnostic Guidelines. Geneva: World Health Organization (1992)

[8] E.R. Neil, Z.K. Winkelmann, J.R. Edler, J Athl Train. 53(3), 279-281 (2018)

[9] K.G. Roos, S.W. Marshall, Sports Med. 44(3), 405-421 (2014)

[10] R. Harbour, J. Miller, BMJ (Clinical research ed.) 323(7308), 334-336 (2001)

[11] D.R. Bonanno, G.S. Murley, S.E. Munteanu et al., J. Foot \& Ankle Res. 8(1), 1-9 (2015)

[12] V. Campanelli, F. Piscitelli, L. Verardi et al., Orthopaedic J. Sports Med. 3(7), 2325967115596517 (2015)

[13] G.J. Dowling, G.S. Murley, S.E. Munteanu et al., J. Foot Ankle Res. 7(1), 53 (2014)

[14] E. Foch, J.A. Reinbolt, S. Zhang et al., Associations between iliotibial band injury status and running biomechanics in women, Gait \& Posture 41(2), 706-710 (2015)

[15] B.W. Fullem, Overuse lower extremity injuries in sports, Clin. Podiatric Med. and Surg. 32(2), 239-251 (2015)

[16] H.R. Galloway, Radiol Clin North Am. 51(3), 511-28 (2013)

[17] S.L. Goffar, R.J. Reber, B.C. Christiansen et al., Phys. Ther. 93(9), 1175-1184 (2013)

[18] Z.Y. Kerr, E. Kroshus, J. Grant et al., J. Athletic Training 51(1), 57-64 (2016)

[19] M. Khan, K. Madden, M.T. Burrus et al., Sports Health 10(2), 169-174 (2018)

[20] M. Koch, J. Zellner, A. Berner et al., Arch Orthop Trauma Surg. 136(3), 353-360 (2016)

[21] R.O. Kollock, C. Andrews, A. Johnston et al., J. Athletic Training (Allen Press) 51(11), 919-926 (2016)

[22] K. Kristenson, J. Bjørneboe, M. Waldén et al., J. Sci. Med. Sport. 19(3), 218-221 (2016)

[23] P. Malliou, S. Rokka, A. Beneka, A. Gioftsidou et al., J. Back Musculoskelet Rehabil. 27(3), 361-370 (2014)

[24] A.M. Pensgaard, A. Ivarsson, A. Nilstad et al., BMJ Open Sport \& Exercise Med. 4(1), e000317 (2018)

[25] M.F. Reinking, T.M. Austin, J. Bennett et al., Inter. J. Sports Phys. Ther. 10(2), 155-167 (2015)

[26] F.J. Sobrino, C. de la Cuadra, P. Guillén, Orthopaedic J. Sports Med. 3(6), 2325967115590114 (2015) 
[27] F.J. Sobrino, P. Guillén, Orthopaedic J. Sports Med. 5(6), 2325967117712704 (2017)

[28] S. Springer, U. Gottlieb, M. Lozin, The scientific world journal 2016, 5939164 (2016)

[29] B.S. Neal, I.B. Griffiths, G.J. Dowling, J. Foot Ankle Res. 19;7(1), 55 (2014)

[30] K.A. Andersen, P.N. Grimshaw, R.M Kelso, D.J. Bentley, Sports Med. - Open, 2, 22 (2016)

[31] M. Tschopp, F. Brunner, Diseases and overuse injuries of the lower extremities in long distance runners, Z Rheumatol. 76(5), 443-450 (2017)

[32] C. Chéron, C. Le Scanff, C. Leboeuf-Yde, Chiropractic \& Manual Therapies 25, 4 (2017) 